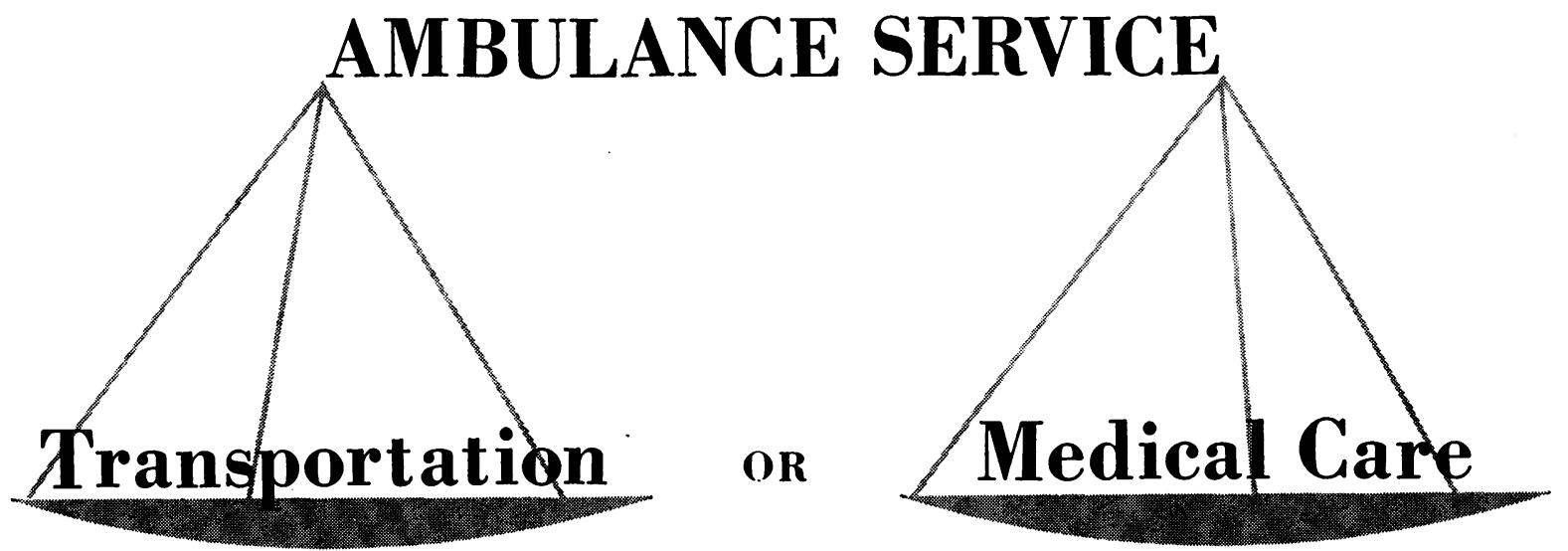

JULIAN A. WALLER, M.D., M.P.H.

7 THE BURGEONING literature on the ad1 ministration of medical care is uniformly silent on the subject of ambulance services. Perhaps the reason for the apparent lack of interest is that the term "medical care" assumes therapeutic skills not possessed by the general public, while the first aid skills of ambulance personnel are presumed to be within the capabilities of almost the entire adult population. However, since first aid and ambulance services frequently represent an initial step in the medical care sequence, they must be considered in comprehensive planning for medical care.

Precursors of modern ambulance units date back more than a thousand years to Italy (1). Originally, the term "ambulance" denoted a mobile hospital, and it was in this context that ambulance services first assumed major significance in 1795 as an innovation of Dominique Jean Larrey, surgeon for Napoleon's armies (2). Dr. Jonathan Letterman introduced ambulances to the American Army during the Civil War (2).

It is widely accepted that the initial medical treatment after illness or injury may be crucial

Dr. Waller is a medical officer in the bureau of occupational health, California State Department of Public Health, Berkeley. to the saving of life and limb. A recent study of automobile fatalities in California emphasizes the importance of the events that occur before the patient reaches the physician or the emergency room (3). This study found that the case-fatality ratio in rural accidents was four times higher than in urban accidents despite the occurrence of less severe accidents and more survivable injuries. 'The higher casefatality ratio in rural areas seemed to be related to the inability to provide adequate first aid procedures, such as maintaining an airway and limiting hemorrhage, and to get the person to a hospital within a reasonable period of time. The following description of several procedures and systems of providing ambulance care shows some existing problems in this initial aspect of the medical care sequence.

\section{Ownership and Organization}

Private ownership for profit. A survey by Krieger (4) in 1958 indicated that throughout the country the majority of ambulance care is under private ownership and that in communitios with fewer than 20,000 people at least 50 percent of the ambulances are operated by morticians as an accessory service. In the rural communities and in many more urban areas, it 
is virtually impossible to operate an ambulance as the sole financial enterprise, and it is not uncommon to find that the ambulance is run as a sideline to sickroom supply rentals, service stations, and various other businesses. Because of the high operating costs and occasional bad publicity associated with a conflict of interest, the general trend since World War II has been for mortuaries to cease the operation of ambulances as soon as arrangements can be made for others to take over.

In communities with a population exceeding 50,000 , a sufficient financial base may exist to permit the operation of a full-time ambulance business. This allows the development of considerable expertise in patient care if the owner is properly motivated and the community shows interest in the value of his activities.

Private voluntary organizations. The oldest known system of ambulance care is the voluntary Misericordia, which still functions in some Italian communities. The volunteers wear masks and robes to avoid identification and embarrassment to the patient. In many small communities throughout the United States and Canada, volunteer firemen, service clubs, or volunteer groups established for the specific purpose of providing ambulance care are offering excellent service. The International Rescue and First-Aid Association, an organization of volunteer first aid groups, provides training and standards of operation for its members.

Private ambulances serving industry. Certain industries with procedures involving high accident risks or in isolated locations maintain ambulances for their own personnel. A number of lumber companies in the United States and Canada keep an ambulance close to their logging operations. Electric utility companies occasionally have ambulances equipped with cardiac defibrillators and crews specially trained in their use. The industrial ambulances occasionally have provided service to the entire community when regular ambulance facilities temporarily have been unavailable.

Hospital ambulances. Until World War II many hospitals had their own ambulances, often staffed with interns or resident physicians. This practice now is rare, probably as a result of the high costs of ambulance operation, a depleted house staff, and the pressure of other duties within the hospital. The growing role of the emergency room as an outpatient facility also may have played a part in making house staffs unavailable for ambulance duty.

Public services. Several municipalities have established ambulance facilities as a taxsupported service to the community. The larger the community, the more likely it is to have city-operated services. Approximately 15 percent of the ambulance organizations in California are run by a unit of government. The actual operation may be under the direction of the police or fire department, the health department, or the city or county hospital. It is not uncommon to find that the task of providing and operating resuscitation equipment is assigned to the fire department, while all other ambulance services may be privately operated or the responsibility of a different government unit. This pattern frequently leads to jurisdictional disputes that may severely impair the quality of patient care at a time when coordination of effort may be most crucial.

\section{Ambulance Personnel}

Recruitment. Among the many concerns of ambulance owners, that of personnel recruitment holds high priority. Salaries are exceedingly low, probably equal to that of the hospital orderly, and hours of duty are long. As a result, most operators complain of an excessively high turnover of help. The exact figures are not available. Where salaries are more substantial, as in the civil service systems of the municipal ambulances, such conditions do not seem to exist.

Because of personnel shortages, many owners are only too happy to accept almost anyone who asks for employment and to provide training either coincidental or subsequent to employment. A few owners have been fortunate enough to obtain off-duty policemen and firemen on a part-time basis. These people have been trained in first aid, often have high physical and mental qualifications, and are especially knowledgeable about the procedures associated with accidents and other emergencies. California's ambulance regulations, established in 1962 , require ambulance personnel to meet certain medical, driving, and moral standards. 
Training. Statewide standards for training exist in only eight States of the United StatesCalifornia, Illinois, Louisiana, Massachusetts, Nevada, Oregon, Texas, and Virginia (5). However, many municipalities have local ordinances setting minimum standards. The ambulance personnel may have no formal training or may, at the other extreme, have extensive experience as a nurse or medical corpsman in the military plus additional inservice training. Most drivers and attendants have at least a standard first aid certificate from the Red Cross (6), and in California an advanced certificate from the Red Cross or Bureau of Mines is required. Physicians and registered nurses serving on ambulances are exempted from this requirement.

The Red Cross developed the advance first aid course to meet the needs of the general population. The course does not, however, meet all the requirements of the person serving in an ambulance. A few areas in which the course is deficient are :

1. Operation of special equipment such as a resuscitator, cardiac massage equipment, and respirator.

2. Obstetrical problems and procedures.

3. Emergency communication procedures between the ambulance and the police, hospital, or other emergency units.

4. Mechanics of extricating persons from a demolished vehicle or building.

5. Handling complex multiple-trauma situations for several injured persons or simultaneous injuries to several organ systems in one person. Both problems are frequently encountered in automobile accidents.

6. "Holding" procedures for patients with severe trauma who may not arrive at a hospital until 3 or 4 hours after injury. A delay of this duration is common in certain rural areas.

7. Elements of safe driving under emergency conditions.

Modification of any Red Cross training program cannot be instituted without approval of the National Research Council. Therefore, many ambulance companies attempt to provide some sort of on-the-job training for their personnel. In addition, the International Rescue and First-Aid Association through its journal The International Rescuer, the Ambulance Association of America through its journal $A i d$, and several State ambulance associations are disseminating useful information about emergency medical procedures. The trauma com- mittee of the American College of Surgeons, several local medical societies, and a few universities and medical schools have given a number of advanced training programs lasting for 1 day to 1 week. Interest among public health departments also is beginning to increase, and training and research programs are being developed in North Carolina, Pennsylvania, Oregon, Ohio, Nevada, and elsewhere, with significant support from the Division of Accident Prevention of the Public Health Service.

One major deficiency exists in the supplementary programs. The rural ambulance operator, like the rural physician, frequently has no one to cover his operation if he leaves his community for training. It may be necessary to develop correspondence courses, itinerant faculty, and other teaching plans to bring the training to the more rural areas. The traffic safety committee of the California Medical Association is preparing a training syllabus which can be used by local medical associations to provide advanced courses for the ambulance personnel in their own communities.

\section{Equipment}

The design of an ambulance depends on the function it is to serve. If it is to be merely a means of transportation to the hospital, a station wagon is sufficient. Obviously, a function approaching that of the mobile hospital, as conceived by Larrey ( $\mathscr{2})$, is desirable, and its design and equipment therefore will be more elaborate. It should be emphasized, however, that the usual limitation of the ambulance is the skill of the personnel rather than the design of the vehicle and other equipment. The cost of a new, fully equipped ambulance may vary from $\$ 5,000$ for an extensively modified station wagon to almost $\$ 15,000$ for some of the commercially produced vehicles.

Most vehicles open from the rear, although a new design has doors on the side. To load either requires considerable skill and energy. This becomes especially true if the ambulance is required to carry four patients, two on litters or gurneys on the floor and two on litters suspended by hooks from the ceiling. Providing adequate care for the patient under such circumstances becomes almost impossible. 
Dr. P. W. Bothwell (y) has described the design of his new vehicle, which may solve many of the problems of rough riding, difficult loading, inaccessability of patients once loaded, and inadequate storage space. The vehicle has hydraulic suspension independent of the body. The height of the body can be raised or lowered for travel in rough terrain, and personnel can walk the litter or gurney directly into the ambulance without any undue lifting or maneuvering on steps. The patient's compartment is readily accessible from the driver's seat.

What equipment is essential for the proper functioning of an ambulance? Because of marked limitation of storage space, even the best equipped vehicle will fall short of being a mobile hospital. The California ambulance regulations, which were developed after extensive consultation with physicians and ambulance operators, require that an ambulance carry the following equipment:

\section{Equipment for patient care}

Two stretchers (one collapsible) plus sufficient linens, blankets, and pillows

Straps and restraints to secure patient to the stretcher

Splints: two of each size: 15, 24, and 54 inches in length

Oxygen and oxygen-breathing apparatus

Airways

Aspiration equipment and emesis basin

Jaw expanders (mouth gags), tongue blades

Bandages (roller, compresses, and large 40-inch triangular bandages for burns), adhesive tape, bandage shears

Tourniquets and hemostats

\section{Safety equipment}

Fire extinguisher

Battery-operated portable light

Spare tire, jack, and tire tools

Seat belts

In addition to this equipment, it may be necessary in some areas to have available flares, ropes, pry bars, resuscitators, a cardiac defibrillator, or other equipment.

Police and fire rescue units occasionally will work out a cooperative agreement with the community ambulance program in which the police or fire rescue unit provides resuscitation services and the ambulance offers all other emergency medical services. As discussed earlier, this procedure has certain inherent difficulties. For this reason it is well to evaluate the equipment and training available to all agencies with responsibility for emergency care in a community. The Gerstenslager Company recently published the findings of a survey of equipment carried by fire rescue units throughout the United States ( 8$)$.

\section{Financial Patterns}

Exhortative papers frequently appear decrying the poor quality of ambulance services. Almost all are based on the assumption that ambulance programs will exist and that the major need is to improve their quality. Actually, if ambulance operation does not prove economically feasible, not only will there be poor service but there may be none at all. This has been amply documented by Caldwell (9). Our concern therefore is with the cost of ambulance care both to the patient and to the operator.

In most areas of the country, a flat fee is charged for using the ambulance in a given geographic area, plus additional charges per mile outside the area and for extra attendants, oxygen, and other supplies. In some communities an extra charge is added for using a red light and a siren, a practice which may promote their unnecessary use by an unscrupulous operator.

Caldwell (9) found that bills for accident trips, especially those in which the patient is carried a long distance, are least likely to be paid ; 77 percent were paid for nonaccident services but only 48 percent for accident care. This situation exists throughout the United States. Since a larger proportion of the ambulance calls in rural areas are accident cases, especially involving nonresident population, and since these more often require longer ambulance trips (3), the already marginal operation in a rural area is likely to suffer still more from financial problems. The following systems of payment and financing currently are used in addition to direct payment.

Guarantee of payment by the hospital. Some ambulance companies have arranged with the hospitals in their communities for the ambulance bill to be incorporated into the hospital's charge to the patient. The hospital, in effect, guarantees payment for use of the ambulance. 
Third-party insurance. Blue Shield and a number of commercial plans provide payment for ambulance service. Many plans, however, do not provide such coverage.

Subscription programs. Approximately a dozen ambulance companies in California and a few in other areas have established prepaid service policies. For a small yearly fee all members of the household are provided with ambulance care up to a stated maximum number of miles. Frequently, a coinsurance clause covers mileage above this maximum. The fees for these programs have been established on a trial and error basis without any actuarial information. Sometimes they have been adequate, and the ambulance services in the community have been substantially strengthened. In other instances they have ended in failure for the program and the ambulance company.

Voluntary communitywide assessment. In some Canadian communities each family is assessed $\$ 5$ a year, a sum sufficient to provide services for the community, especially with volunteer personnel.

Government assistance. Where ambulances are not operated directly by a city or county, arrangement for a subsidy may exist. This sometimes takes the form of a standard sum paid monthly in exchange for transportation of indigent patients. More frequently, a flat fee per patient is charged no matter what the distance, or reimbursement of a certain percent of the usual charge to the patient provided the patient has not paid the bill himself within 30 to 60 days. It has been estimated that communities underwriting ambulance services in this way spend approximately $\$ 3,000$ to $\$ 5,000$ yearly per ambulance. The minimum yearly cost to cities or counties that own and operate ambulances is $\$ 20,000$ to $\$ 25,000$ per ambulance.

\section{The Patient}

Comparatively little has been documented about the patients who use ambulances. No utilization rates have been published for either urban or rural areas, although a study by the Public Health Service of ambulance services in San Francisco and one the California State Department of Health is doing on the use of ambulance services in a rural community will provide this information (10). Preliminary reports from this study indicate that utilization rates vary from 5 per 1,000 population for children under age 10 to 200 per 1,000 for people over age 80. Approximately 45 percent of the calls are for accidents and 20 percent for cardiovascular or respiratory diseases. Half of the patients who died during a trip or after using an ambulance had a cardiovascular or respiratory condition.

It can be estimated that approximately 3 people per 100 will use an ambulance in a community during any one year. The actual utilization rate depends on the age distribution of the population and the presence or absence of major roadways or hazardous industries. Where such roadways exist, a larger proportion of the patients carried will be nonresidents of the community. Waller and associates (3) reported that nonpedestrian automobile fatalities in rural areas more frequently involve nonresidents than such fatalities in urban areas.

Emergency calls often account for only a small proportion of ambulance trips. Routine transfers between a hospital and a nursing home, a private residence, or another hospital frequently represent the "bread and butter" of ambulance business. In Caldwell's study (9) more than 93 percent of the mileage traveled by one ambulance company was for routine transfers. This pattern varies, however, from one community to another.

\section{Regulation of Ambulances}

Local ordinances regulating the operation of ambulances have been enacted in many cities and counties and in a few States. Most are concerned only with the use of red lights and sirens. An unpublished survey in 1962 by Dr. Irma C. West, California Department of Public Health, found that only four States (Louisiana, Massachusetts, Texas, and Washington) had statewide regulations giving any consideration to personnel or equipment. A more recent survey (5) indicates that this number had increased to eight as of January 1965. The latter study provides an excellent description of ambulance services in North Carolina. Lehman and Hollingsworth (11) and Hampton (6) have summarized much of the information about local 
ordinances. More recently, the Ambulance Association of America began collecting copies of State and local regulations. As a result of cooperative activity by the Division of Accident Prevention of the Public Health Service, the National Safety Council, the American College of Surgeons, and other groups, suggested uniform ambulance regulations now are available.

Invariably, the subject of ambulances and their regulation brings up the question of the need for speed, red light, and siren. Curry and Lyttle (12), in a study of 2,500 ambulance runs, found that undue haste almost never was helpful and occasionally was harmful to the patient. West and associates (13) recently studied 5,000 ambulance trips in which the maximum posted speed limits were exceeded while carrying a patient. The preliminary results of West's study show that while speed was not found to be harmful, neither was it helpful in 92 percent of the trips. Most of the patients for whom speed was helpful had some form of poisoning.

It also was found that the policemen who called the ambulances frequently were responsible for the decision to exceed speed limits. This has been confirmed by another study (10). Under such circumstances, it makes little sense to penalize the drivers for speeding. Rather we need some sound analysis of the evaluation process which leads either the policemen or ambulance personnel to a decision that speed is necessary. Attempts must be made to examine separately the effects of speed in traveling to the scene of the accident or illness, speed in carrying the patient to the hospital, use of red light and siren to clear traffic only, and use of red light and siren in conjunction with speed above the posted limits.

\section{False Assumptions That Hinder Progress}

The regulation of ambulance services should be designed to provide better care of the patient. This can be done only by considering such services as a bona fide and important area of medical care and by improving the quality of personnel training and equipment available. Three assumptions or stumbling blocks exist in achieving this goal:

1. The assumption that the usual procedures for providing emergency care in an accident or illness are known. Actually, little has been documented about patient characteristics and who does what at the scene of an accident or en route to the hospital. For example, ambulance operators are being taught routine obstetrics without knowledge of whether the average obstetrical patient in the ambulance has routine or unusual obsterical problems. The problems associated with extricating the injured from a badly damaged vehicle are almost totally unexplored.

2. The assumption that the regulation of ambulances will solve most of the needs of emergency medical care without consideration of the important area of communications. How rapidly is the ambulance called? Will the hospital be ready and willing to accept the patient when he arrives? Will a physician be available? It is frustrating to hear of patients who are moved quickly and efficiently to the hospital and then must wait for a physician. The solution to this problem does not lie in the regulation of ambulances. Emergency medical care is broader than ambulance services alone. On the other hand, it begins before arrival at the emergency room, which is the starting point for most of the literature on medical care administration.

3. The assumption that conditions in urban and rural areas will be the same and that similar training will suffice for ambulance personnel in both areas. As has been apparent throughout this paper, there is good reason to suspect that this is not true.

In short, the answer to poor emergency medical services lies in a basic understanding that such services must be considered as a real area of medical care requiring greater skills than those learned in the routine first aid course. These services require sound financial nourishment to thrive. Some of the assumptions which suggest that enough information now exists and that it need only be applied must be challenged. Application of what is known is needed, but research and evaluation also are needed. It must be recognized that improvement will come through programs that provide for education and face-to-face communication between ambulance personnel and the medical profession, hospital administrators, and other groups providing emergency services rather than through regulations alone. 


\section{Summary}

Ambulance service frequently is the first phase of the medical care sequence and therefore must be considered as a bona fide area of medical care. Such services currently are provided through a variety of ownership patterns including voluntary, private, and government operation. Approximately 15 percent of the ambulance organizations in California are run by a unit of government. The actual operation may be under the direction of the police or fire department, the health department, or the city or county hospital.

Many ambulance programs, particularly in the more rural areas, are beset by problems of inadequate finances, inadequately trained personnel, and rapid personnel turnover because of low salaries. These are being mitigated to some degree through the development of advanced training programs and through subscription and insurance programs, voluntary community assessments, and government subsidies. It has been estimated that communities underwriting ambulance services spend approximately $\$ 3,000$ to $\$ 5,000$ yearly per ambulance. The minimum yearly cost to cities or counties that own and operate ambulances is $\$ 20,000$ to $\$ 25,000$ per ambulance.

Currently, little is known about the people who use ambulances or about existing procedures from the moment a person is found to need care until he arrives at the hospital. Only eight States-California, Illinois, Louisiana, Massachusetts, Nevada, Oregon, Texas, and Virginia-regulate the quality of ambulance personnel and equipment. Public health agencies, safety groups, and the medical profession now have begun to share concern about the quantity and quality of ambulance care, resulting during the past 5 years in several research projects, improved training, and a model ambulance ordinance.

\section{REFERENCES}

(1) Turrini, A.: The ambulance-for profit or compassion? Aid, November-December 1963, p. 18.

(2) Curry, G. J.: The immediate care and transportation of the injured. Bull Amer Coll Surg 44: 32, 34, 64-67 (1959).

(3) Waller, J. A., Curran, R., and Noyes, F.: Traffic deaths; a preliminary study of urban and rural fatalities in California. Calif Med 101: 272-276 (1964).

(4) Krieger, W. M.: Ambulance operation. Mortuary Management, October 1958, p. 16.

(5) Cadmus, R. R., and Ketner, J. H.: Organizing ambulance services in the public interest. North Carolina Hospital Education and Research Foundation, Inc., Chapel Hill, N.C., January 1965.

(6) Hampton, O. P., Jr.: Transportation of the injured. Bull Amer Coll Surg 45 : 55-59 (1960).

(7) Bothwell, P. W.: Ambulance design. In Proceedings of Seventh Stapp Car Crash Conference, edited by D. M. Severy. Charles C Thomas, Springfield, Ill., 1965, pp. 324-344.

(8) Gerstenslager Company: A survey of emergency rescue vehicle equipment and operation. Wooster, Ohio.

(9) Caldwell, L. A.: Ambulance services and traffic casualties. Ont Med Rev 28:172-182 (1961).

(10) Waller, J. A., Garner, R., and Lawrence, R.: Utilization of ambulance services in a rural community. Amer J Public Health. In press.

(11) Lehman, S. P., and Hollingsworth, K. H.: Ambulance service in Seattle. Public Health Rep 75 : 343-351 (1960).

(12) Curry, G. J., and Lyttle, S. N.: The speeding ambulance. J Mich Med Soc 56:1140-1141 (1957) ; Amer J Surg 95 : 507-511 (1958).

(13) West, I. C., et al.: Speeding ambulance survey : a preliminary report. Aid, September-October 1964, pp. 10, 14, 22. 